\title{
Effects of forage provision to dairy calves on growth performance and rumen fermentation: A meta-analysis and meta-regression
}

\author{
M. Imani, ${ }^{*}$ M. Mirzaei, † B. Baghbanzadeh-Nobari, $\ddagger$ and M. H. Ghaffari $\S^{1}$ \\ *Department of Animal Science, College of Agriculture and Natural Resources, University of Tehran, Karaj 3158711167-4111, Iran \\ †Department of Animal Science, Faculty of Agriculture and Natural Resources, Arak University, Arak 38156-88349, Iran \\ ‡Department of Animal Sciences, College of Agriculture, Ataturk University, 25240 Erzurum, Turkey \\ §Department of Agricultural, Food and Nutritional Science, University of Alberta, Edmonton, T6G 2P5, Canada
}

\begin{abstract}
A meta-analysis of the potential effect of forage provision on growth performance and rumen fermentation of dairy calves was conducted using published data from the literature (1998-2016). Meta-regression was used to evaluate the effects of different forage levels, forage sources, forage offering methods, physical forms of starter, and grain sources on the heterogeneity of the results. We considered 27 studies that reported the effects of forage provision to dairy calves. Estimated effect sizes of forage were calculated on starter feed intake, average daily gain (ADG), feed efficiency (FE), body weight $(\mathrm{BW})$, and rumen fermentation parameters. Intake of starter feed, $\mathrm{ADG}, \mathrm{BW}$, ruminal $\mathrm{pH}$, and rumen molar proportion of acetate increased when supplementing forage but FE decreased. Heterogeneity (the amount of variation among studies) was significant for intake of starter feed, ADG, FE, final BW, and rumen fermentation parameters. Improving overall starter feed intake was greater in calves offered alfalfa hay compared with those offered other types of forages. During the milk feeding and overall periods, improving ADG was greater for calves fed a high level of forage $(>10 \%$ in dry matter) compared with those fed a low level of forage ( $\leq 10 \%$ in dry matter) diets. The advantages reported in weight gain at a high level of forage could be due to increased gut fill. Improving overall ADG was lower for calves offered forages with textured starter feed compared with ground starter feed. The meta-regression analysis revealed that changes associated with forage provision affect FE differently for various forage sources and forage offering methods during the milk-feeding period. Forage sources also modulated the effect of feeding forage on ruminal $\mathrm{pH}$ during the milk-feeding period. In conclusion, forage has the po-
\end{abstract}

Received June 4, 2016.

Accepted October 9, 2016.

${ }^{1}$ Corresponding author: morteza $1 @ u a l b e r t a . c a$ tential to affect starter feed intake and performance of dairy calves, but its effects depend on source, level, and method of forage feeding and physical form of starter feed independently of grain sources included in the starter feed.

Key words: calf, forage, meta-analysis, physical form

\section{INTRODUCTION}

Concentrate feeds provide readily fermentable carbohydrates to support rumen fermentation (Khan et al., 2008); however, feeding calves only concentrate feeds may reduce ruminal $\mathrm{pH}$ (Daneshvar et al., 2015) and can cause hyperkeratinization as well as clumping of the ruminal papillae (Bull et al., 1965), especially when calves are fed finely ground starter diets (Greenwood et al., 1997). Provision of forage to young calves early in life has been shown to improve solid feed consumption (Castells et al., 2012; EbnAli et al., 2016), ADG (Khan et al., 2011; Castells et al., 2012; Montoro et al., 2013), and BW (Coverdale et al., 2004; Beiranvand et al., 2014).

The literature on the effects of feeding forage during the transition from liquid to solid feed is inconclusive. Some studies have reported a decrease (Hill et al., 2008, 2009, 2010); others have reported an increase (Khan et al., 2011; Castells et al., 2012; Beiranvand et al., 2014; Daneshvar et al., 2015), and others have found no difference (Jahani-Moghadam et al., 2015; Mirzaei et al., 2015) on calf performance when comparing absence or presence of forage in the diet of calves. It appears that the effects of forage provision to young calves depend on the level of forage in the starter feed (Nemati et al., 2016), forage sources (Castells et al., 2012), physical form of starter feed (Mirzaei et al., 2016), and forage offering method (i.e., TMR vs. free-choice provision). Forage level seems likely to be among the most important factors influencing growth performance of dairy calves (Nemati et al., 2016), and it has been widely recognized that forage provision increases postweaning total DMI (Castells et al., 2012; Terré et al., 2013). 
Meta-analyses represent an efficient tool to resolve conflicts in the literature (Lean et al., 2009). The aim of this study was to understand the general relationships between forage provision and performance of dairy calves using meta-analytic methods. A secondary objective was to examine effects of forage levels, forage sources, forage offering method, and physical forms of starter feed on the heterogeneity responses to forage.

\section{MATERIALS AND METHODS}

\section{Study Selection}

A literature search and screening process (limiting results to studies published between 1998 and 2016) was conducted. To be included in the meta-analysis, studies had to evaluate (and report) the effects of forage supplementation of calves during the milk-feeding and postweaning periods. Quality assessment criteria included randomization of treatment assignments, blinding to treatment application and analysis of data, statistical analysis, and comparability of treatment groups at study enrollment (Lean and Rabiee, 2011). Studies were included in the meta-analysis if they involved dairy calves (birth to 12 wk of age; veal calves or fattening bulls were excluded). The studies had to include a concurrent control group and forage supplementation groups or at least changes in forage inclusion levels. Finally, the studies had to report at least one of the performance outcomes of interest: starter feed intake, ADG, or feed efficiency (FE) during the milkfeeding, postweaning, or both periods; weaning BW, final $\mathrm{BW}$, and rumen fermentation parameters (i.e., $\mathrm{pH}$, total VFA concentration, and molar proportions of individual VFA), along with a measure of variance or a $P$-value for effect comparison between treatment and control groups. In total, 21 articles (27 separate studies) were found to meet these inclusion criteria for the meta-analysis.

\section{Selection for Data Extraction}

Data were collated from the eligible studies. A template for data extraction was drafted, which included number of calves per treatment group, mean, and standard error. If the standard error was not published, it was estimated from either the exact $P$-values or other measures of variance; otherwise, the data were excluded. In the case where a $P$-value was reported as less than a number (i.e., $P<0.05$ ), that value was used as the $P$-value for the standard error calculation. Other factors that influenced the outcomes of interest were included in the data extraction process, includ- ing forage level, forage sources, forage offering method, physical form of starter feed, and grain sources. Forage inclusion level ( $>10$ or $\leq 10 \%$ ), forage sources (alfalfa hay or other hays, i.e., ryegrass hay, oat hay, barley straw, triticale silage, corn silage), forage offering method (TMR or free-choice provision), physical form of starter feed (ground, pelleted, or textured), and grain sources (barley, corn, or mixed grains) were noted for each treatment mean to allow subsequent exploration of their effects using meta-regression.

\section{Statistical Analysis}

A meta-analysis was conducted on the extracted outcomes of the metafor package of $\mathrm{R}$ i386 3.0.1; the package is available via the Comprehensive $\mathrm{R}$ Archive Network (CRAN, https://cran.r-project.org; Viechtbauer, 2010). The Metafor package provides functions for fitting various models. The various meta-analytic models can be fitted with the rma() function; CMA was used for estimates of unreported standard errors in some studies. A random effect model was conducted for each treatment to estimate the effect size, 95\% CI, and statistical significance of effect size (Nasrollahi et al., 2015).

Under a fixed-effect model, we assume that the true effect size for all studies is identical, and the only reason the effect size varies between studies is sampling error (error in estimating the effect size). Therefore, when assigning weights to different studies, we can largely ignore the information in smaller studies because we have better information about the same effect size in the larger studies. In contrast, under a random-effects model, the goal is not to estimate one true effect, but to estimate the mean of a distribution of effects. Because each study provides information about a different effect size, we wanted to be sure that all these effect sizes were represented in the summary estimate. Therefore, we cannot discount a small study by giving it a very small weight (the way we would in a fixed-effect analysis). The estimate provided by that study may be imprecise, but it is information about an effect that no other study has estimated. By the same logic, we cannot give too much weight to a very large study (the way we might in a fixed-effect analysis). Our goal was to estimate the mean effect in a range of studies, and we do not want that overall estimate to be overly influenced by any one of them (Borenstein et al., 2009). The effect size was computed by logarithmic transformation of the ratio (Nasrollahi et al., 2015), and mean ( $\mu$ ) difference was computed for each variable as follows:

$$
\text { Mean difference }=\mu 1-\mu 2 \text {. }
$$


The $I^{2}$ statistic describes the percentage of total variation across studies due to heterogeneity rather than chance; it was calculated as follows:

$$
I^{2}=\left(\frac{Q-(k-1)}{Q}\right) \times 100,
$$

where $Q$ is the $\chi^{2}$ heterogeneity statistic and $k$ is the number of studies. Uncertainty intervals for $I^{2}$ (dependent on $Q$ and $k$ ) were calculated. Publication bias was investigated both graphically with funnel plots, and statistically using tests from Begg and Manumdar (1994) and Egger et al. (1997). In the case of a significant publication bias, the number of studies needed to reverse the reported findings (the fail-safe $\mathrm{n}$ ) was calculated based on Rosenthal's methods (Rosenthal, 1979).

\section{RESULTS}

A summary of the studies including a description of the dietary intervention of each study regarding forage levels, forage sources, forage offering methods, the physical form of starter feed, and grain sources is presented in Table 1. Diets contained from 2.5 to $70 \%$ forage (DM basis), consisting of alfalfa hay, ryegrass hay, oat hay, barley straw, triticale silage, and corn silage, and were offered in 2 forms (TMR or free-choice) along with ground, pelleted, and textured starter feeds. A summary of the experimental parameters illustrates the mean and range of key data in those studies (Supplemental Table S1, https://doi.org/10.3168/jds.201611561; Table 1).

\section{Meta-Analysis and Meta-Regression for Intake and Performance}

The meta-analysis findings of the effect of forage on starter intake, ADG, FE, and $\mathrm{BW}$ are presented in Table 2. Starter intake increased $(P<0.01)$ with forage supplementation of calves; forage provision increased intake of starter feed by $0.027,0.201,0.083 \mathrm{~kg} / \mathrm{d}$ for the milk-feeding, postweaning, and overall periods, respectively. Average daily gain was not affected $(P=0.50)$ by forage provision during the milk-feeding period, but increased $(P<0.05)$ during the postweaning period by $0.054 \mathrm{~kg} / \mathrm{d}$. Feed efficiency was not affected $(P=0.11)$ by forage provision during the milk-feeding period; however, forage supplementation decreased FE (0.013 and 0.012 , respectively) during the postweaning $(P=$ $0.05)$ and overall $(P<0.01)$ periods. Weaning and final BW increased $(P<0.01)$ with forage supplementation in starter diets.
Forest plots for the effect of forage provision to young calves on starter feed intake (Figure 1A), ADG (Figure 1B), FE (Figure 2A), and final BW (Figure 2B), revealed considerable variation between studies. In addition, as reported in Table 2, the heterogeneity for starter feed intake and ADG was different $(P<0.01)$. Heterogeneity for FE was significant $(P<0.05)$ and tended to be different $(P=0.08)$ for final BW. Heterogeneity for starter feed intake was at the highest level (82-96\%), and for FE was at the lowest level (27-34\%). Consequently, data related to starter feed intake, ADG, and $\mathrm{FE}$ were subjected to a further meta-regression analysis to identify the sources of this variation.

Forage level modulated starter feed intake during the milk-feeding and postweaning periods, with greater intake of starter feed in diets at a high level of forage $(>10 \%$ of DM) compared with the low inclusion level $(\leq 10 \%$ of DM). Forage sources, forage offering method, physical form of starter feed, and grain sources did not affect intake of starter feed during the milk-feeding period (Table 3). Forage sources also influenced the effect of forage on postweaning starter feed intake. The increase in starter feed intake was greater $(P=0.02)$ in calves offered alfalfa hay compared with those offered other types of forages during the postweaning period (Table 3). The increase in starter feed intake was greater for the ground and pelleted starter feeds compared with the textured starter feed in forage-supplemented calves during the postweaning $(P=0.01)$ and overall $(P<$ 0.01 ) periods (Table 3 ). The increase in starter feed intake was lower $(P<0.01)$ for calves offered forages as TMR compared with those offered free-choice forages during the overall period (Table 3).

The meta-regression analysis revealed that changes in forage similarly affected ADG for forage source, forage offering method, physical form of starter, and grain source, and differently affected ADG for various forage levels during the milk-feeding period (Table 4). However, forage levels, forage sources, forage offering methods, the physical form of starter, and grain sources did not modulate the effects of forage on ADG during the postweaning period (Table 4). During the milk-feeding $(P=0.01)$ and overall $(P=0.03)$ periods, improving ADG was greater for calves fed a high level of forage $(>10 \%$ in DM) compared with those fed a low level of forage ( $\leq 10 \%$ in DM) diets (Table 4). Improving ADG was lower $(P<0.01)$ for calves offered forages as TMR compared with those offered free-choice forages during the overall period (Table 4). During the overall period, improving ADG was lower $(P<0.01)$ for calves offered forages with textured starter feed compared with ground starter feed, but was similar in pelleted starter feed compared with ground starter feed (Table 4). 
META-ANALYSIS ON FORAGE FEEDING IN CALVES

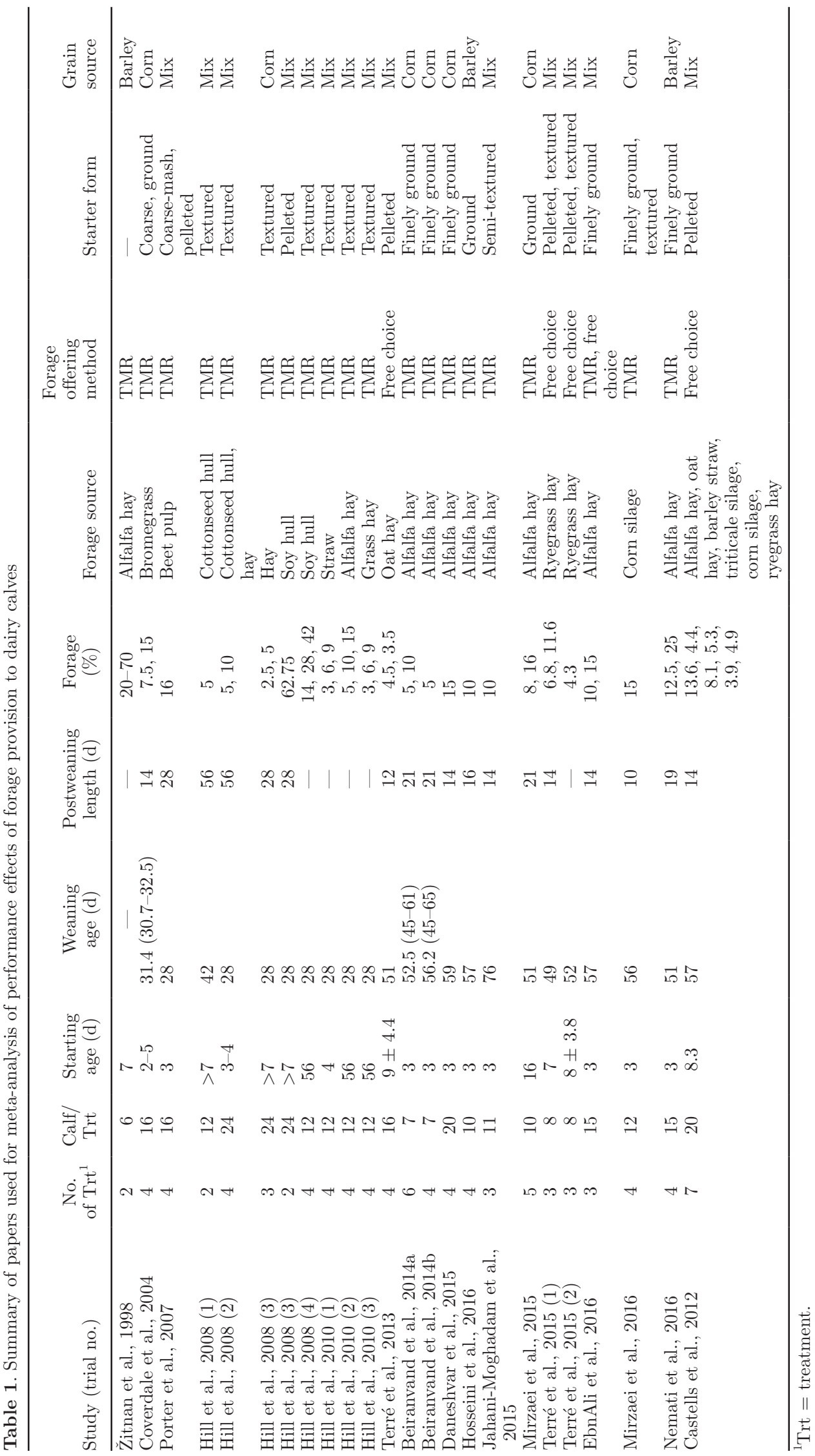


Table 2. The effect size estimates of forage on starter feed intake, ADG, feed efficiency, weaning BW, and final BW in dairy calves derived from meta-analysis

\begin{tabular}{|c|c|c|c|c|c|c|c|}
\hline Item & $\operatorname{MD}^{1}(95 \% \mathrm{CI})$ & $\begin{array}{l}\text { Studies } \\
\text { (n) }\end{array}$ & Effect size $(95 \% \mathrm{CI})$ & $\mathrm{SE}$ & $P$-value & $I^{2}(\%)^{2}$ & $P$-value \\
\hline \multicolumn{8}{|l|}{ Starter intake $(\mathrm{kg} / \mathrm{d})$} \\
\hline Overall & $0.083(0.029,0.137)$ & 42 & $-0.072(-0.120,-0.023)$ & 0.039 & 0.01 & 81.6 & $<0.01$ \\
\hline \multicolumn{8}{|l|}{$\mathrm{ADG}(\mathrm{kg} / \mathrm{d})$} \\
\hline Milk-feeding period & $0.009(-0.017,0.035)$ & 38 & $0.019(-0.037,-0.075)$ & 0.028 & 0.50 & 71.9 & $<0.01$ \\
\hline \multicolumn{8}{|l|}{ Feed efficiency } \\
\hline Milk-feeding period & $-0.010(-0.023,0.033)$ & 37 & $-0.021(-0.047,0.005)$ & 0.013 & 0.11 & 26.8 & 0.05 \\
\hline Postweaning & $-0.013(-0.025,-0.001)$ & 38 & $-0.030(-0.059,-0.001)$ & 0.015 & 0.05 & 33.8 & 0.03 \\
\hline Overall & $-0.012(-0.019,-0.005)$ & 44 & $-0.027(-0.044,-0.010)$ & 0.009 & $<0.01$ & 29.7 & 0.02 \\
\hline \multicolumn{8}{|l|}{ BW (kg/d) } \\
\hline At weaning & $2.430(1.330,3.530)$ & 16 & $0.038(0.021,0.056)$ & 0.009 & $<0.01$ & 16.0 & 0.30 \\
\hline Final & $4.772(3.260,6.280)$ & 29 & $0.057(0.039,0.074)$ & 0.009 & $<0.01$ & 28.4 & 0.08 \\
\hline
\end{tabular}

${ }^{1} \mathrm{MD}=$ mean difference.

${ }^{2}$ Degree of heterogeneity among studies included in the meta-analysis.

The meta-regression analysis revealed that changes in forage similarly affected FE at forage levels, the physical form of starter, and grain sources, and differently affected FE for various forage sources and forage offering method during the milk-feeding period (Table $5)$. Decreasing FE was greater $(P=0.04)$ for calves offered alfalfa hay compared with those offered other types of forages during the milk-feeding period (Table $5)$. In addition, decreasing $\mathrm{FF}$ was lower $(P<0.01)$ for calves offered forages as TMR compared with those offered free-choice forages during the milk-feeding period (Table 5). During the overall period, decreasing FE tended to be lower $(P=0.06)$ for calves offered forages as TMR compared with those offered free-choice forages (Table 5). However, forage levels, forage sources, forage offering methods, the physical form of starter, and grain sources did not modulate the effects of forage on postweaning FE and final BW of dairy calves (Table $5)$.

\section{Meta-Analysis and Meta-Regression for Rumen Fermentation}

The meta-analysis findings for the effect of feeding forage on rumen fermentation parameters are presented in Table 6 . Ruminal $\mathrm{pH}$ increased $(P<0.01)$ with supplementation of forage in the starter diets; feeding forage increased ruminal $\mathrm{pH}$ by 0.298 for the milk-feeding period and by 0.456 for the postweaning period. Supplementation of forage in the starter diets decreased $(P<0.01)$ total VFA concentration in the rumen by $10.6(\mathrm{mmol} / \mathrm{L})$ for the milk-feeding period and tended $(P=0.08)$ to decrease by $13.2(\mathrm{mmol} / \mathrm{L})$ for the postweaning period.
The molar proportion of acetate in the rumen increased $(P<0.01)$ with supplementation of forage in the starter diets; feeding forage increased acetate by $3.448(\mathrm{~mol} / 100 \mathrm{~mol})$ for the milk-feeding period and by $2.410(\mathrm{~mol} / 100 \mathrm{~mol})$ for postweaning period. The molar proportion of propionate in the rumen was not affected by feeding forage during the milk-feeding period $(P=$ $0.16)$ or postweaning period $(P=0.78)$. The molar proportion of butyrate in the rumen was not affected $(P=$ 0.11 ) by feeding forage during the milk-feeding period; however, supplementation of forage in the starter diets decreased butyrate by $3.33(\mathrm{~mol} / 100 \mathrm{~mol})$ for the postweaning period. Supplementation of forage in the starter diets increased $(P<0.01)$ acetate to propionate ratio in the rumen by 0.18 for the milk-feeding period, but the acetate to propionate ratio was not affected ( $P=0.88)$ by feeding forage during the postweaning period.

In addition, as reported in Table 6, the heterogeneity for ruminal $\mathrm{pH}$ (milk-feeding period), total VFA, acetate, butyrate (milk-feeding period and postweaning), and acetate to propionate ratio (milk-feeding period) were different $(P<0.05)$. Heterogeneity was at the highest level for butyrate (99\%) and at the lowest level for acetate (44\%). The high heterogeneity qualified the variables to be explored with meta-regression for some important variables in feeding forage condition. As a result, data of ruminal $\mathrm{pH}$, total VFA, and acetate, butyrate, and acetate to propionate ratio were subjected to a meta-regression for the effect of forage nested within forage levels, forage source, and physical forms of starter.

The meta-regression analysis revealed that changes in forage similarly affected the ruminal molar propor- 
A

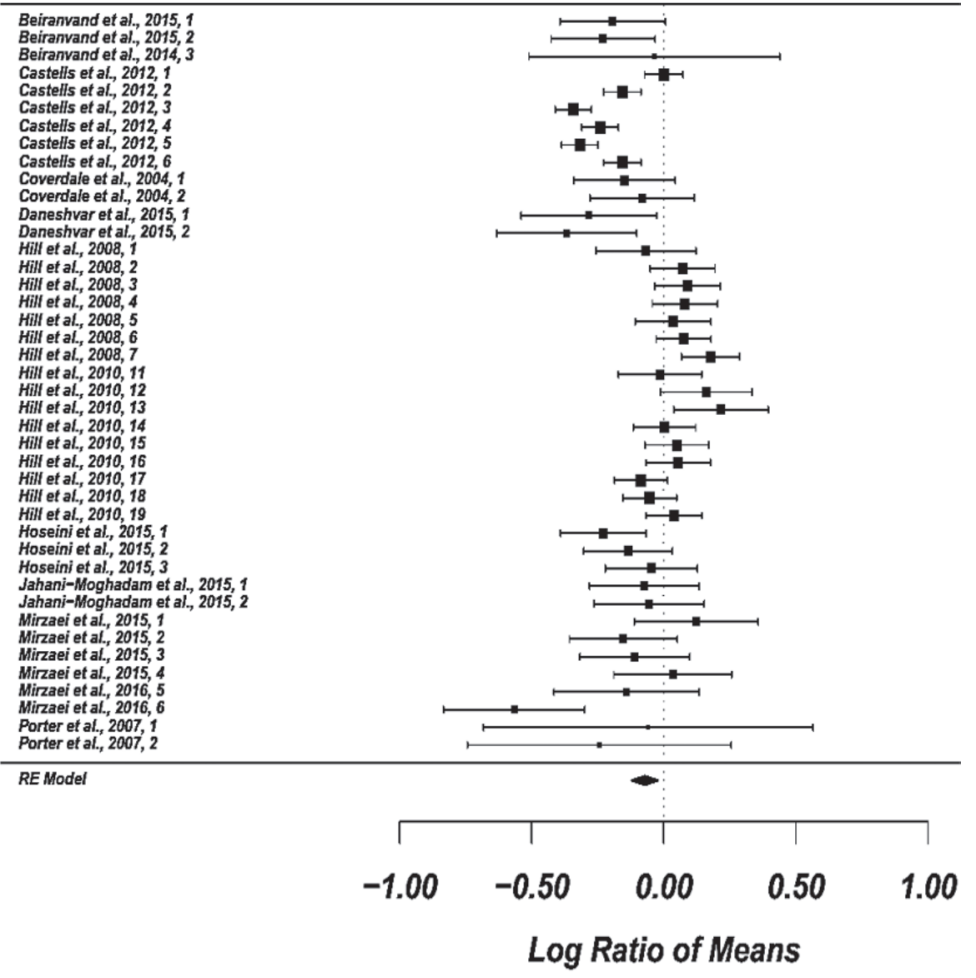

B

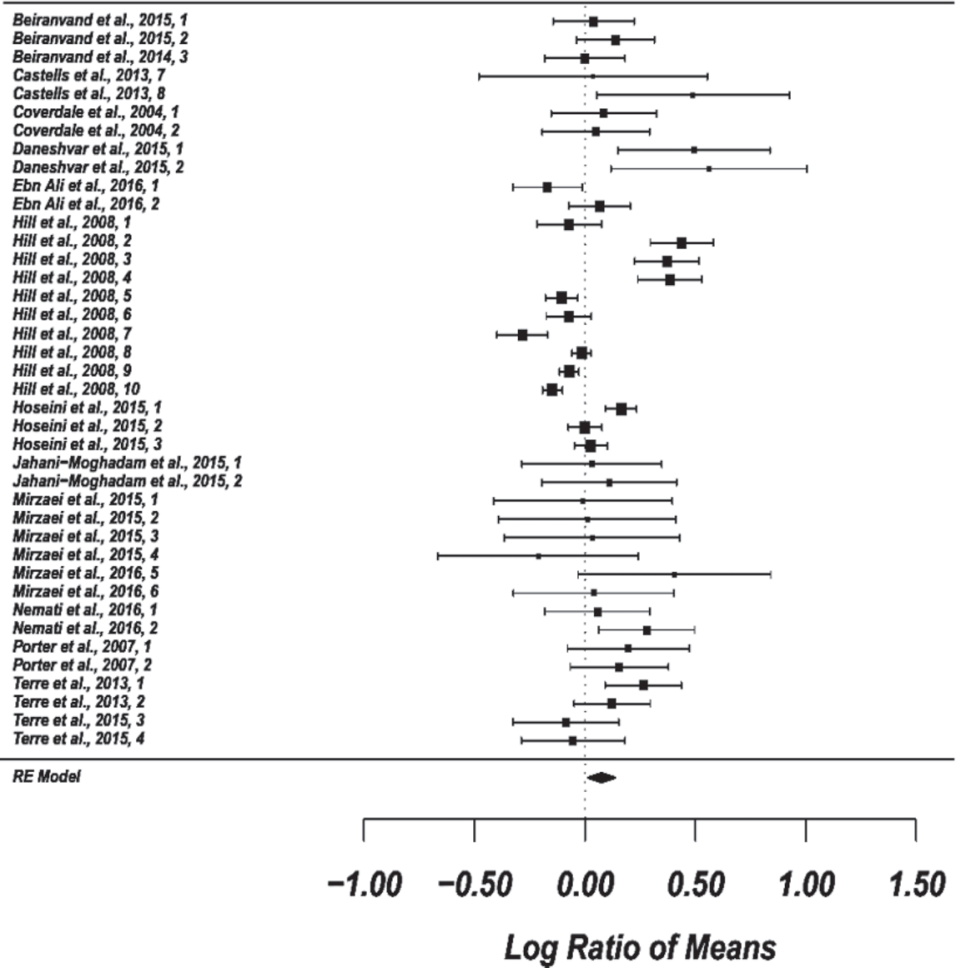

Figure 1. Forest plot of the effect of forage on (A) starter feed intake $(\mathrm{kg} / \mathrm{d})$ and $(\mathrm{B}) \mathrm{ADG}(\mathrm{kg} / \mathrm{d})$ in dairy calves during the overall period. The $\mathrm{x}$-axis shows standardized mean difference (standardized using the z-statistic); thus, points to the left of the line represent a reduction in the trait, whereas points to the right of the line indicate an increase. Each square represents the mean effect size for that study, and the size of the square reflects the relative weighting of the study to the overall effect size estimate with larger squares representing greater weight. The upper and lower limit of the line connected to the square represents the upper and lower 95\% CI for the effect size. The diamond at the bottom represents the $95 \% \mathrm{CI}$ for the overall estimate, and the dotted vertical line represents a mean difference of zero or no effect. 
A

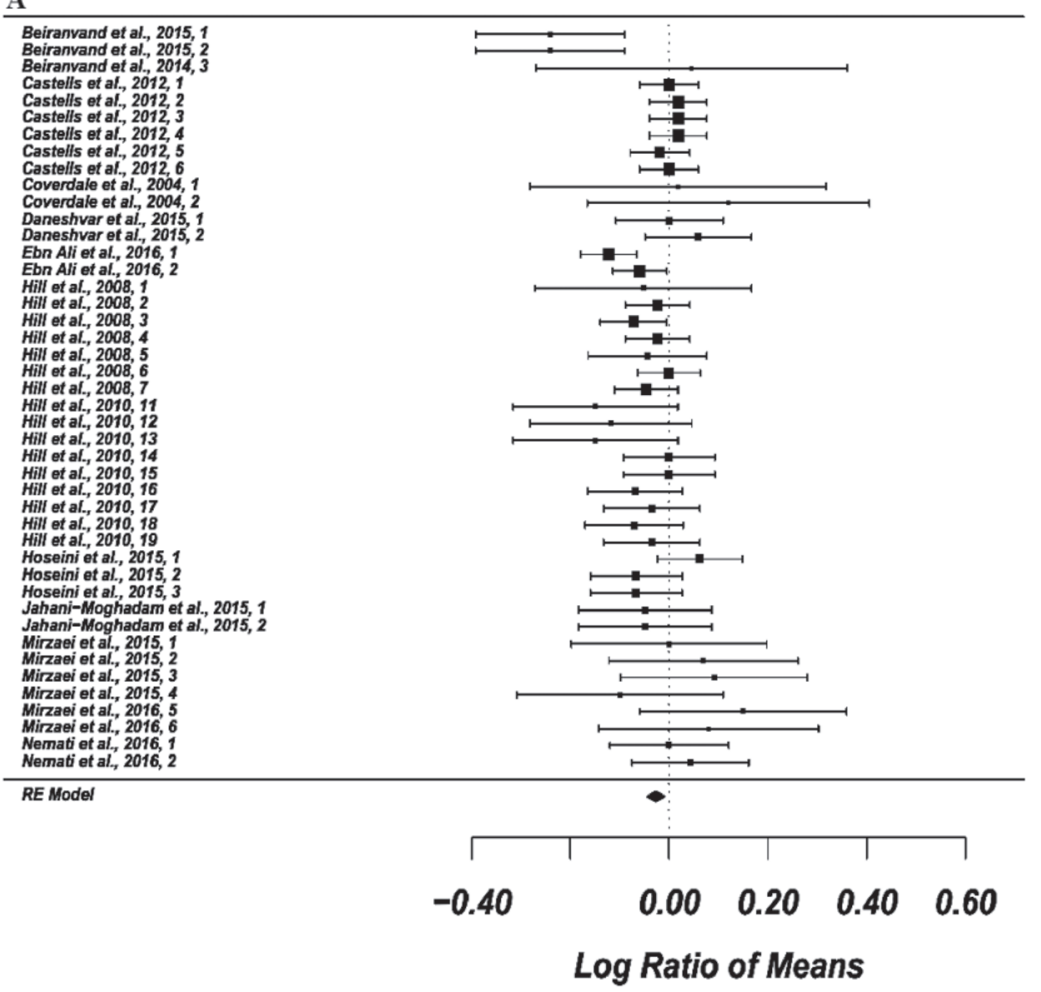

B

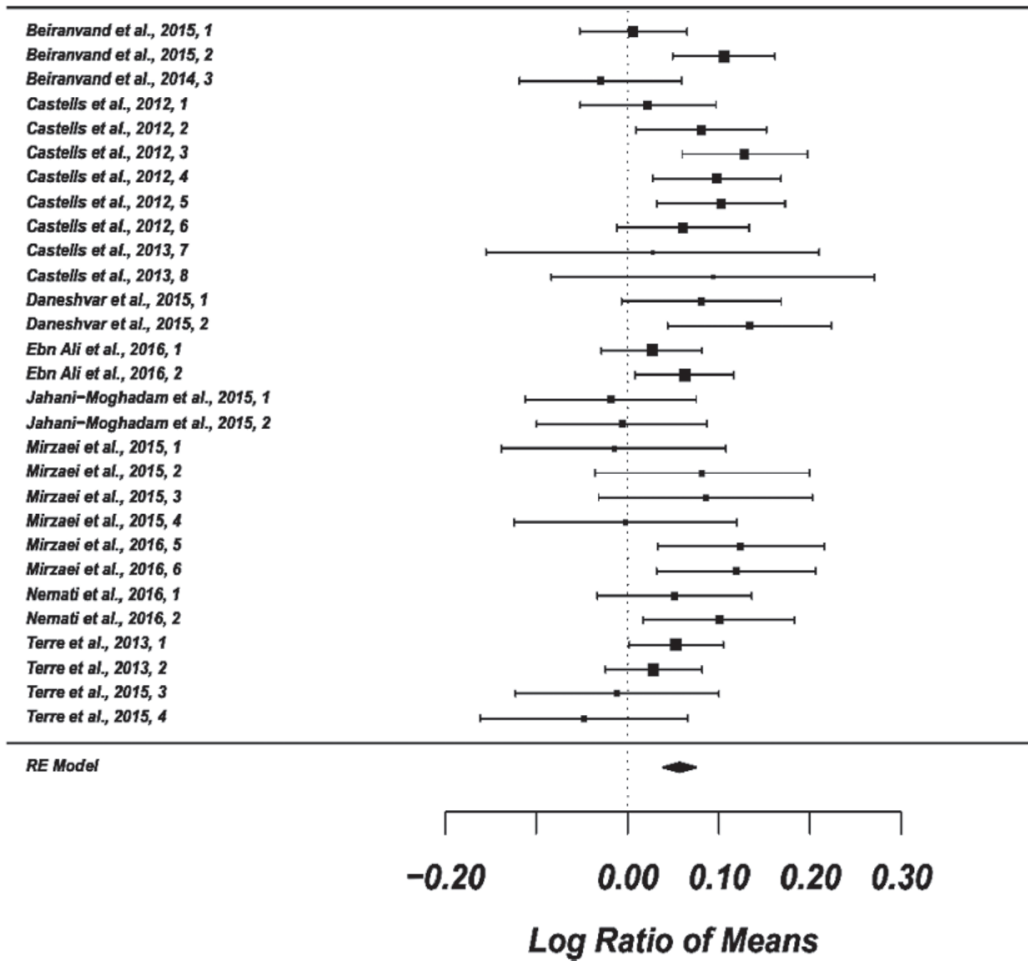

Figure 2. Forest plot of the effect of forage on (A) feed efficiency and (B) final BW (kg) in dairy calves during the overall period. The x-axis shows standardized mean difference (standardized using the z-statistic); thus, points to the left of the line represent a reduction in the trait, whereas points to the right of the line indicate an increase. Each square represents the mean effect size for that study, and the size of the square reflects the relative weighting of the study to the overall effect size estimate with larger squares representing greater weight. The upper and lower limit of the line connected to the square represents the upper and lower 95\% CI for the effect size. The diamond at the bottom represents the 95\% CI for the overall estimate, and the dotted vertical line represents a mean difference of zero or no effect. 
META-ANALYSIS ON FORAGE FEEDING IN CALVES

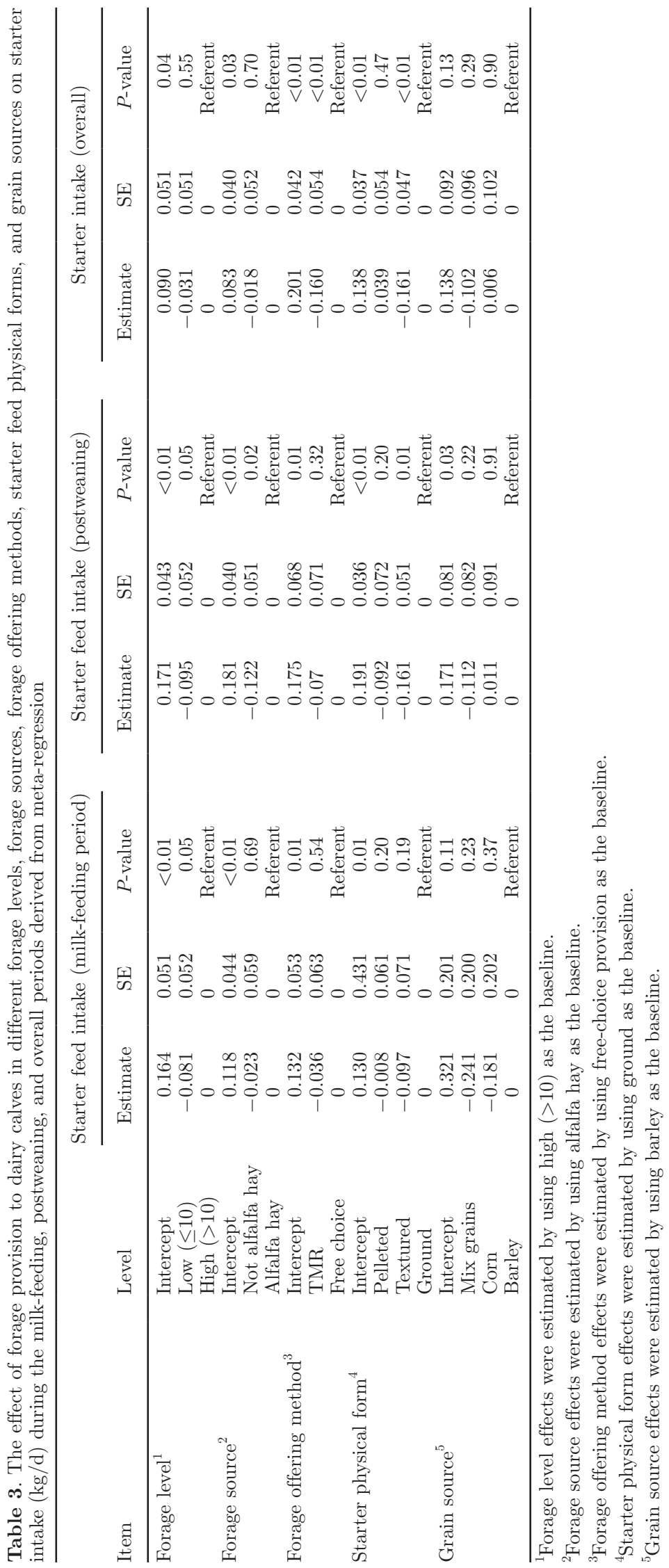


IMANI ET AL.

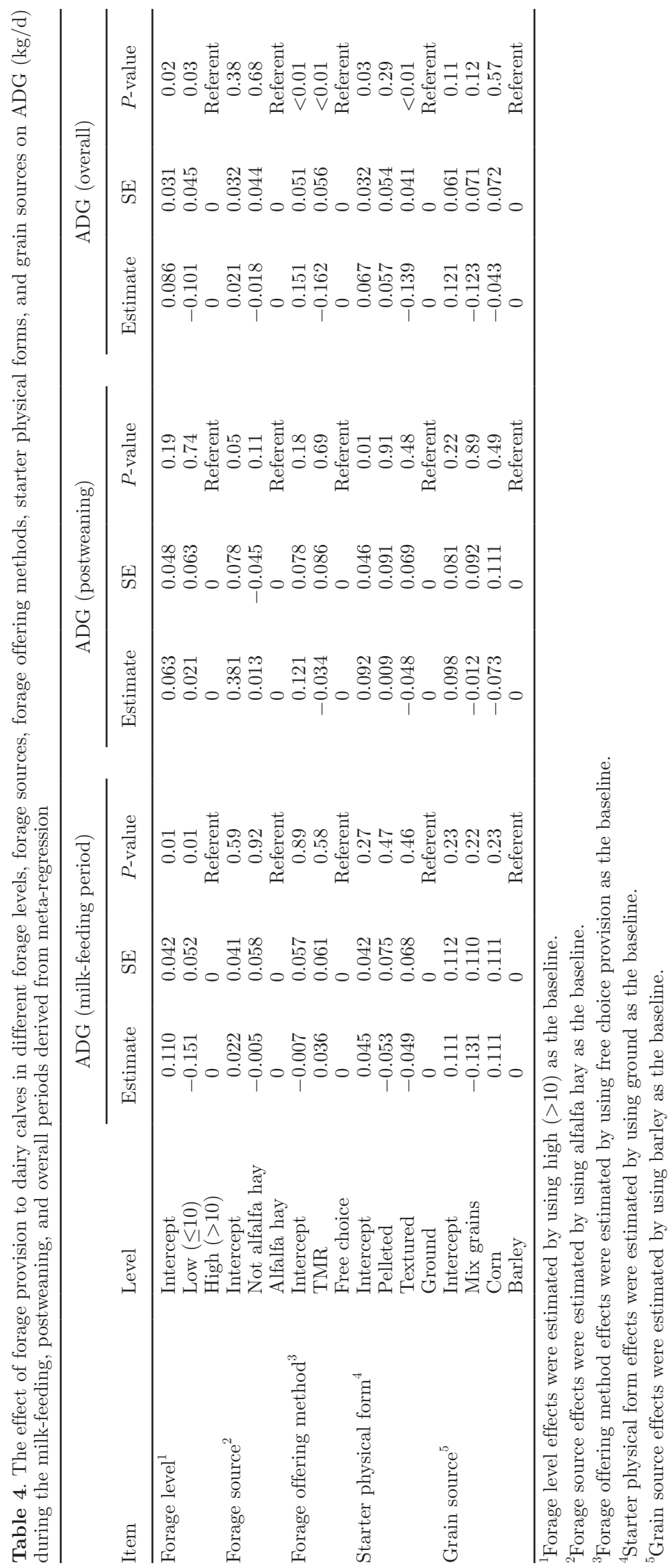




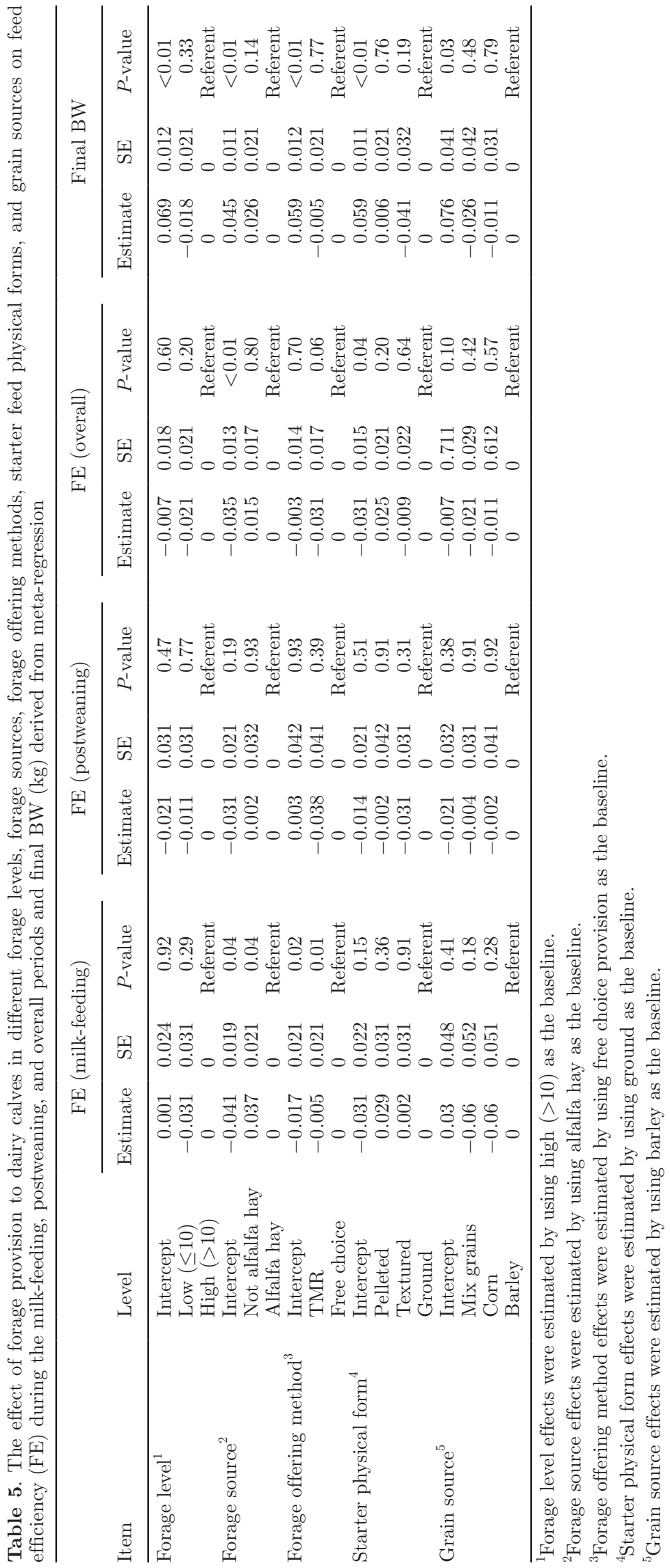


tion of acetate for forage sources, and differently affected $(P<0.05)$ acetate level for various forage levels for the milk-feeding period (Table 7 ). However, forage levels and forage sources did not modulate the effects of feeding forage on the molar proportions of propionate and butyrate in the rumen of dairy calves (Table 7). Increasing the molar proportion of ruminal acetate was lower for calves fed a high level of forage $(>10 \%$ in DM) compared with those fed a low level of forage $(\leq 10 \%$ in DM) diets (Table 7$)$. Forage sources also influenced the effect of feeding forage on ruminal $\mathrm{pH}$ during the milk-feeding period (Table 7).

\section{DISCUSSION}

\section{Calf Performance}

Feeding forage increased postweaning and overall starter intake by 0.201 and $0.08 \mathrm{~kg} / \mathrm{d}$, respectively. Meta-analysis in the current study clearly proved an increase in starter intake through forage supplementation in dairy calves. The positive effects of forage on the intake of solid feed may be related to the improvement in ruminal environment and enhanced muscular development of the rumen (Khan et al., 2011; Castells et al., 2013). Coverdale et al. (2004) found that forage provision increased total DMI in calves through positive effects on the ruminal environment $(\mathrm{pH}$ and acid load). The effect of feeding forage on starter feed intake also varied among studies. For instance, Hill et al. (2008) reported that feeding forage to preweaning dairy calves reduced starter feed and overall DM consump- tion, which was explained by the low fermentation rates of fibrous material in the rumen. In contrast, others (Coverdale et al., 2004; Beiranvand et al., 2014; EbnAli et al., 2016) reported an increase in starter feed intake. Taking into account the potential variation across studies due to grain sources in the present analysis did not reveal a change in starter feed intake. However, across all of the studies considered herein, starter feed intake outcome was heterogeneous, which indicates that the response to supplementation with forage was not uniformly consistent and may depend on other factors such as forage levels, forage sources, and physical form of starter feeds used.

The increasing effects of forage on starter feed intake at high levels of forage ( $>10 \%$ of DM) as well as providing forage along with a ground or pelleted starter feed compared with a textured starter feed were an important outcome of our study. Overall starter feed intake responses to forage supplementation were greater as a free-choice provision than TMR, probably due to the inclusion level of forage. From the perspective of the outcome of starter feed intake, our data suggest that increasing alfalfa hay is a useful tool to enhance starter feed intake in dairy calves supplied with ground or pelleted starter feeds. Recently, Nemati et al. (2016) indicated that feed intake might be affected by rations differing in alfalfa hay level so that providing calves with $25 \%$ alfalfa hay can improve total DMI and weight gain in dairy calves. Indeed, a large consumption of alfalfa hay was expected because voluntary intake of legumes is reported to be greater than that of grasses (Castells et al., 2012).

Table 6. The effect size estiwmates of feeding forage on rumen fermentation in dairy calves derived from meta-analysis

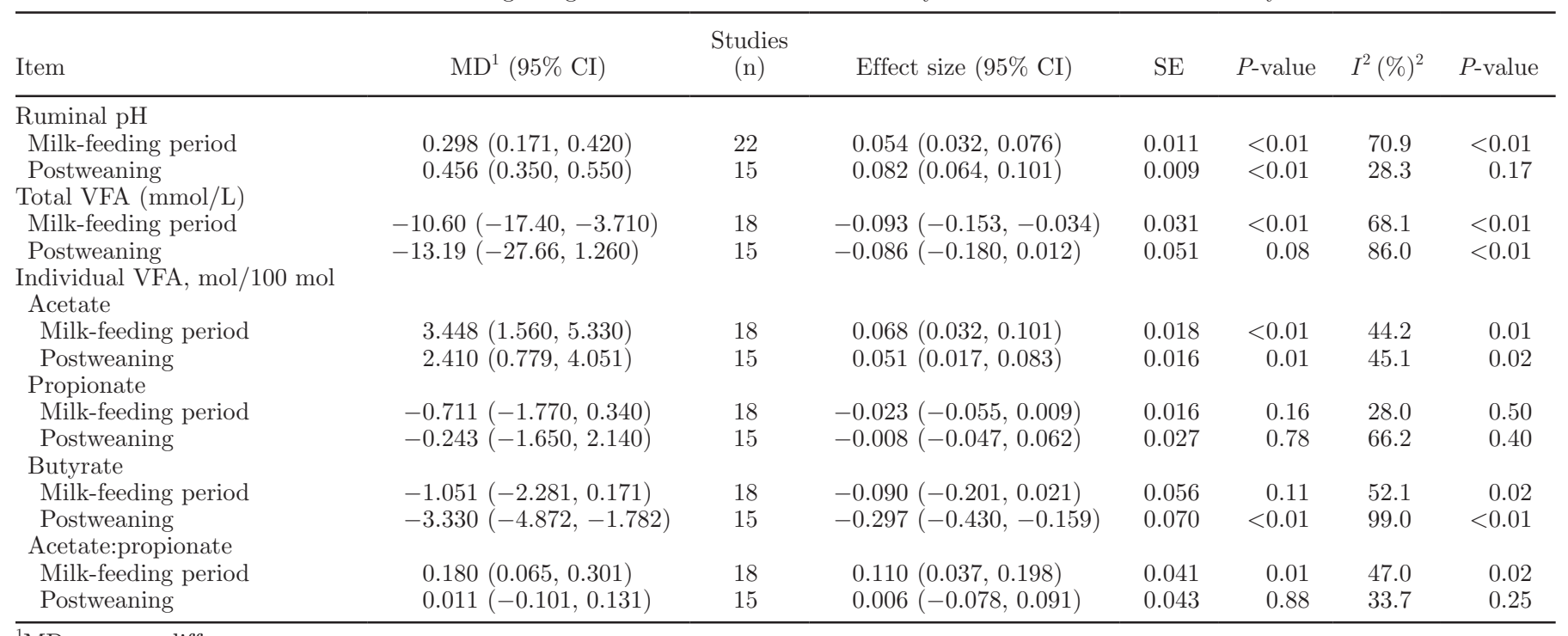

${ }^{1} \mathrm{MD}=$ mean difference.

${ }^{2}$ Degree of heterogeneity among studies included in the meta-analysis. 


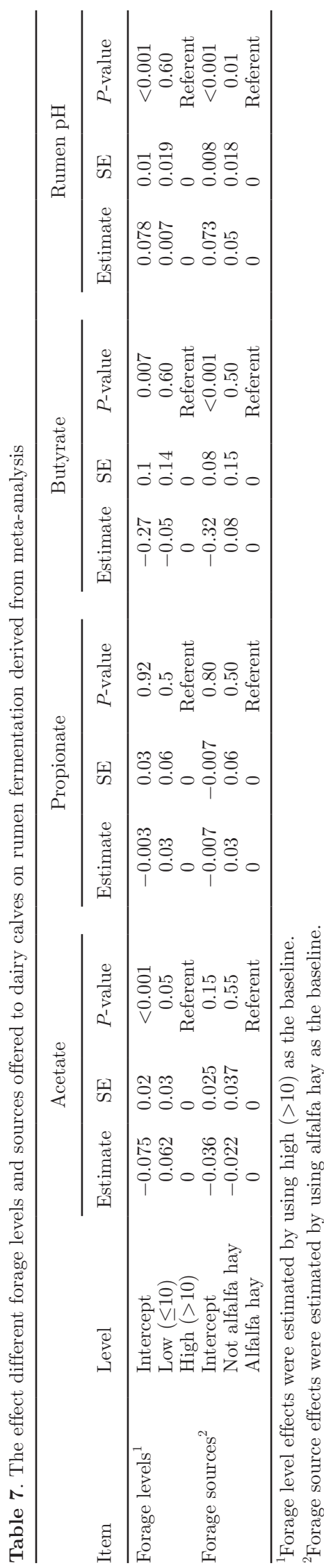

The type of processing used and the physical form of starter diet can alter the rumen fermentation pattern and passage rate of digesta (Huntington, 1997), thereby affecting solid feed consumption in young calves (Bateman et al., 2009). In the current study, calves supplied with ground or pelleted starter feeds supplemented with forage had enhanced feed consumption compared with those receiving textured starter feed with forage sources. Dairy calves can experience ruminal acidosis similar to mature animals, and forages may play a role in helping calves overcome this challenge. Previous researchers (Greenwood et al., 1997; Beharka et al., 1998) have documented that rumen $\mathrm{pH}$ is often well below 6.0 in young calves, particularly those fed finely ground diets. The form of the starter feed also influences the risk of acidosis. For example, finely ground starter feed that is high in rapidly fermentable carbohydrates could reduce ruminal $\mathrm{pH}$ and starter feed intake (GhassemiNejad et al., 2012). Further, pelleting may increase starch degradation by increasing surface area and through gelatinization of the starch granule (DehghanBanadaky et al., 2007), negatively influencing rumen fermentation and feed intake (Bach et al., 2007).

Rapid fermentation of ingested calf starter feed causes an increased concentration of VFA and decreased $\mathrm{pH}$ in the underdeveloped rumen (Laarman et al., 2012). Therefore, the reasons for the improvement in starter feed intake with increasing forage might be attributed the ameliorating effects of forage on drops in ruminal $\mathrm{pH}$ found in calves fed ground or pelleted starter feeds than those fed textured diets. In previous studies, a positive effect of alfalfa hay on stimulating starter feed intake was observed when alfalfa hay was supplemented to a finely ground starter feed (Beiranvand et al., 2014; Daneshvar et al., 2015; EbnAli et al., 2016) for young calves, but this was not the same in a textured starter feed (Hill et al., 2008, 2010). Terré et al. (2015) concluded that calves fed a texturized starter feed with or without straw supplementation had similar starter feed intake compared with the same nutrients and ingredients presented in a pelleted starter feed offered with chopped straw.

The results of our meta-analysis show that forage provision to dairy calves had a beneficial effect on ADG. The improvement of ADG by more than $50 \mathrm{~g} / \mathrm{d}$ with feeding forage could be explained by a greater starter feed intake. Previous studies have documented controversial effects of forage on ADG of dairy calves as some studies reported a decrease in ADG (Hill et al., 2010), whereas others have reported an increase (Khan et al., 2011; Castells et al., 2012; Beiranvand et al., 2014). The ADG responses to forage supplementation were heterogeneous, and meta-regression analysis showed that forage levels during the milk-feeding period and 
forage levels, forage offering method, and physical form of starter feed during the overall period were the source of heterogeneity of ADG. Meta-regression analysis showed that improving ADG was greater for calves fed a high level of forage ( $>10 \%$ in DM) as well as providing forage along with a ground or a pelleted feed compared with textured starter feed. Moreover, improving overall ADG responses to forage supplementation were greater when provided as free choice than in a TMR. These results indicate that forage supplementation can promote BW gain in calves more efficiently in the ground or pelleted starter feeds supplemented with high levels of forage.

However, due to supplementing the high level of forage $(>10 \%$ of DM), gut fill could be a confounding factor when determining forage effects on improving ADG and BW of dairy calves. There is a common perception that an increase in BW by forage feeding can be due to greater gut fill and increased weight of gastrointestinal tissues (Hill et al., 2008; Khan et al., 2011; Mirzaei et al., 2015). Therefore, when forage intake is higher than $10 \%$ of the total solid feed intake, the advantages reported in weight gain could be due to gut fill.

We also found a decrease in FE with feeding forage. The decreasing effect of forage on FE could be explained by greater starter feed intake in forage-supplemented calves. The FE responses to forage supplementation were heterogeneous, and meta-regression analysis showed that forage sources and forage offering method were sources of heterogeneity of FE.

\section{Ruminal Fermentation}

Available studies demonstrate the negative effects of low ruminal $\mathrm{pH}$ on performance and health of developing calves. Previous studies have shown that ruminal $\mathrm{pH}$ ranges from 5.4 to 5.6 in preweaned calves (Greenwood et al., 1997; Daneshvar et al., 2015), increasing to above 5.6 to 5.8 as the calves reach 10 to 12 wk of age (Beharka et al., 1998; Lesmeister and Heinrichs, 2004). Reasons for low ruminal $\mathrm{pH}$ in preruminant calves include (1) the rapid fermentation of carbohydrate by rumen bacteria in calves consuming high-grain diets (Lesmeister and Heinrichs 2004; Laarman and Oba, 2011), (2) production of VFA that may exceed the absorptive capacity of the rumen epithelium when it is underdeveloped (Baldwin et al., 2004), and (3) limited production of saliva in young calves and saliva that contains less bicarbonate than saliva of older calves (Kay, 1960).

We found an increase in ruminal $\mathrm{pH}$ with supplementing forage during the milk-feeding period and postweaning period, confirming findings of previous studies (Castells et al., 2012; Mirzaei et al., 2015; Nemati et al.,
2016). The possible reasons for the increased ruminal $\mathrm{pH}$ following forage provision to preruminant calves have been multifactorial. Including forage in calves' starter that does not ferment rapidly may be beneficial in raising and stabilizing ruminal $\mathrm{pH}$ (Khan et al., 2016). The greater ruminal $\mathrm{pH}$ in forage-supplemented calves could also be explained by its effect on chewing (eating and ruminating) activity and, therefore, elevating rumen $\mathrm{pH}$ through buffer content in the saliva flow (Nemati et al., 2016).

Improved ruminal $\mathrm{pH}$ may also be attributed to the removal of the keratinized layer and dead cells from the rumen wall, as induced by forage (Bull et al., 1965), thereby increasing the ability to absorb VFA and maintain rumen $\mathrm{pH}$ in dairy calves (Mirzaei et al., 2015). Castells et al. (2013) reported increased expression of monocarboxylate transporter-1 (MCT1, a VFA transporter) in the rumen epithelium of forage-supplemented calves than control calves. Monocarboxylate transporter-1 plays a direct role in VFA absorption in the rumen and its increased expression might aid in the maintenance of rumen pH (Graham et al., 2007) in forage-supplemented calves.

Particle size in calf starters must be adequate to stimulate chewing, which then results in saliva production for buffering and more nearly normalizing rumen fermentation. However, few studies have been reported the physical form of starter and just because a starter was labeled "texturized" in a study does not mean it has adequate texture. Rumen fermentation starts at a very young age and VFA can be found in the rumen of calves as early as the second week of life (Beharka et al., 1998). It has been argued that the ruminal concentrations of VFA do not accurately reflect the rate of fermentation due to their rapid clearance (Mirzaei et al., 2015) and the great variability in volume of rumen digesta liquid (Hall et al., 2015), but the ratio between individual VFA may be indicative of the type of fermentation. Similar to what was found by meta-analyses, greater acetate proportions have usually been observed in forage-supplemented diets (Castells et al., 2013; EbnAli et al., 2016; Mirzaei et al., 2016; Nemati et al., 2016). Cellulolytic microorganisms are more prevalent in higher forage diets, leading to greater degradation of fiber and resulting in increased molar proportions of acetate in the rumen (Žitnan et al., 1998).

\section{CONCLUSIONS}

This meta-analysis revealed improvements in starter feed intake, $\mathrm{ADG}$, final $\mathrm{BW}$, ruminal $\mathrm{pH}$, the molar proportion of acetate, and the acetate to propionate ratio in the rumen with feeding forage, but a depression 
of FE. Forage level was a potentially important source of heterogeneity, in which starter feed intake increased with the provision of forage to calves, particularly alfalfa hay, for diets containing a high level of forage $(>10 \%)$. However, the improvement reported in ADG at a high level of forage could be due to increased gut fill. Furthermore, the improvement in starter feed intake and final BW due to forage supplementation was evident for calves offered free-choice forage. Results demonstrate that the effect of forage on calf performance was more evident during the postweaning period and this was especially clear in ADG. In conclusion, forage has the potential to affect intake of starter feed and performance of dairy calves but its effects are modulated by forage level, source, forage offering method, and physical form of starter.

\section{ACKNOWLEDGMENTS}

The authors gratefully acknowledge the scientific assistance and advice from Alex Bach (Department of Ruminant Production-IRTA, Barcelona, Spain) and A. M. Khan (Animal Nutrition and Health Group, Grasslands Research Centre, AgResearch, Palmerston North, New Zealand).

\section{REFERENCES}

Bach, A., A. Gimenez, J. L. Juaristi, and J. Ahedo. 2007. Effects of physical form of a starter for dairy replacement calves on feed intake and performance. J. Dairy Sci. 90:3028-3033.

Baldwin, R. L., VI, K. R. McLeod, J. L. Klotz, and R. N. Heitmann. 2004. Rumen development, intestinal growth and hepatic metabolism in the pre- and postweaning ruminant. J. Dairy Sci. 87:E55E65.

Bateman, H. G., T. M. Hill, J. M. Aldrich, and R. L. Schlotterbeck. 2009. Effects of corn processing, particle size, and diet form on performance of calves in bedded pens. J. Dairy Sci. 92:782-789.

Begg, C. B., and M. Manumdar. 1994. Operating characteristics of a rank correlation test for publication bias. Biometrics 50:1088-1101.

Beharka, A. A., T. G. Nagaraja, J. L. Morrill, G. A. Kennedy, and R. D. Klemm. 1998. Effects of form of the diet on anatomical, microbial and fermentative development of the rumen of neonatal calves. J. Dairy Sci. 81:1946-1955.

Beiranvand, H., G. R. Ghorbani, M. Khorvash, A. Nabipour, M. Dehghan-Banadaky, A. Homayouni, and S. Kargar. 2014. Interactions of alfalfa hay and sodium propionate on dairy calf performance and rumen development. J. Dairy Sci. 97:2270-2280.

Borenstein, M., L. V. Hedges, J. P. T. Higgins, and H. R. Rothstein. 2009. Subgroup analyses. Pages 149-186 in Introduction to MetaAnalysis. John Wiley \& Sons, Chichester, UK.

Bull, L. S., L. J. Bush, J. D. Friend, B. Harris, and E. W. Jones. 1965. Incidence of ruminal parakeratosis in calves fed different rations and its relation to volatile fatty acid absorption. J. Dairy Sci. 48:1459-1466.

Castells, L., A. Bach, G. Araujo, C. Montoro, and M. Terré. 2012. Effect of different forage sources on performance and feeding behavior of Holstein calves. J. Dairy Sci. 95:286-293.

Castells, L., A. Bach, A. Aris, and M. Terré. 2013. Effects of forage provision to young calves on rumen fermentation and development of the gastrointestinal tract. J. Dairy Sci. 96:5226-5236.
Coverdale, J. A., H. D. Tyler, J. D. Quigley III, and J. A. Brumm. 2004. Effect of various levels of forage and form of diet on rumen development and growth in calves. J. Dairy Sci. 87:2554-2562.

Daneshvar, D., M. Khorvash, E. Ghasemi, A. H. Mahdavi, B. Moshiri, M. Mirzaei, A. Pezeshki, and M. H. Ghaffari. 2015. The effect of restricted milk feeding through conventional or step-down methods with or without forage provision in starter feed on performance of Holstein bull calves. J. Anim. Sci. 93:3979-3989.

Dehghan-Banadaky, M., R. Corbett, and M. Oba. 2007. Effects of barley grain processing on productivity of cattle. Anim. Feed Sci. Technol. 137:1-24.

EbnAli, A., M. Khorvash, G. R. Ghorbani, A. Nargeskhani, M. Malekkhahi, M. Mirzaei, A. Pezeshki, and M. H. Ghaffari. 2016. Effects of forage offering method on performance, rumen fermentation, nutrient digestibility, blood metabolites, and nutritional behavior in Holstein dairy calves. J. Anim. Physiol. Anim. Nutr. (Berl.). 100:820-827. 10.1111/jpn.12442.

Egger, M., G. Davey Smith, M. Schneider, and C. Minder. 1997. Bias in meta-analysis detected by a simple, graphical test. BMJ 315:629-634.

Ghassemi-Nejad, J., N. Torbatinejad, A. A. Naserian, S. Kumar, J. D. Kim, Y. H. Song, C. S. Ra, and K. I. Sung. 2012. Effects of processing of starter diets on performance, nutrient digestibility, rumen biochemical parameters and body measurements of Brown Swiss dairy calves. Asian-australas. J. Anim. Sci. 25:980-987.

Graham, C., I. Gatherar, I. Haslam, M. Glanville, and N. L. Simmons. 2007. Expression and localization of monocarboxylate transporters and sodium/proton exchangers in bovine rumen epithelium. Am. J. Physiol. Regul. Integr. Comp. Physiol. 292:R997-R1007.

Greenwood, R. H., J. L. Morril, E. C. Titgemeyer, and G. A. Kennedy. 1997. A new method of measuring diet abrasion and its effect on the development of the forestomach. J. Dairy Sci. 80:2534-2541.

Hall, M. B., T. D. Nennich, P. H. Doane, and G. E. Brink. 2015. Total volatile fatty acid concentrations are unreliable estimators of treatment effects on ruminal fermentation in vivo. J. Dairy Sci. 98:3988-3999.

Hill, T. M., H. G. Bateman, J. M. Aldrich, and R. L. Schlotterbeck. 2008. Effects of the amount of chopped hay or cottonseed hulls in a textured calf starter on young calf performance. J. Dairy Sci. 91:2684-2693.

Hill, T. M., H. G. Bateman, J. M. Aldrich, and R. L. Schlotterbeck. 2009. Roughage for diets fed to weaned dairy calves. Prof. Anim. Sci. 25:283-288

Hill, T. M., H. G. Bateman, J. M. Aldrich, and R. L. Schlotterbeck. 2010. Roughage amount, source, and processing for diets fed to weaned dairy calves. Prof. Anim. Sci. 26:181-187.

Hosseini, S. M., G. R. Ghorbani, P. Rezamand, and M. Khorvash. 2016. Determining optimum age of Holstein dairy calves when adding chopped alfalfa hay to meal starter diets based on measures of growth and performance. Animal 10:607-615. https://doi. org/10.1017/S1751731115002499.

Huntington, G. B. 1997. Starch utilization by ruminants: From basics to the bunk. J. Anim. Sci. 75:852-867.

Jahani-Moghadam, M. E., M. Mahjoubi, F. Hossein-Yazdi, C. Cardoso, and J. K. Drackle. 2015. Effects of alfalfa hay and its physical form (chopped versus pelleted) on performance of Holstein calves. J. Dairy Sci. 98:4055-4061.

Kay, R. N. 1960. The rate of flow and composition of various salivary secretions in sheep and calves. J. Physiol. 150:515-537.

Khan, M. A., A. Bach, D. M. Weary, and M. A. G. von Keyserlingk. 2016. Invited review: Transitioning from milk to solid feed in dairy heifers. J. Dairy Sci. 99:885-902.

Khan, M. A., H. J. Lee, W. S. Lee, H. S. Kim, S. B. Kim, S. B. Park, K. S. Baek, J. K. Ha, and Y. J. Choi. 2008. Starch source evaluation in calf starter: II. Ruminal parameters, rumen development, nutrient digestibilities, and nitrogen utilization in Holstein calves. J. Dairy Sci. 91:1140-1149.

Khan, M. A., D. M. Weary, and M. A. G. von Keyserlingk. 2011. Hay intake improves performance and rumen development of calves fed higher quantities of milk. J. Dairy Sci. 94:3547-3553. 
Laarman, A. H., and M. Oba. 2011. Short communication: Effect of calf starter on rumen $\mathrm{pH}$ of Holstein dairy calves at weaning. J. Dairy Sci. 94:5661-5664.

Laarman, A. H., T. Sugino, and M. Oba. 2012. Effects of starch content of calf starter on growth and rumen $\mathrm{pH}$ in Holstein calves during the weaning transition. J. Dairy Sci. 95:4478-4487. /https:/ doi.org/10.3168/jds.2011-4822.

Lean, I. J., and A. R. Rabiee. 2011. Effect of feeding biotin on milk production and hoof health in lactating dairy cows: A quantitative assessment. J. Dairy Sci. 94:1465-1476.

Lean, I. J., A. R. Rabiee, T. F. Duffield, and I. R. Dohoo. 2009. Invited review: Use of meta-analysis in animal health and reproduction: Methods and applications. J. Dairy Sci. 92:3545-3565.

Lesmeister, K. E., and A. J. Heinrichs. 2004. Effects of corn processing on growth characteristics, rumen development, and rumen parameters in neonatal dairy calves. J. Dairy Sci. 87:3439-3450.

Mirzaei, M., M. Khorvash, G. R. Ghorbani, M. Kazemi-Bonchenari, A. Riasi, A. Nabipour, and J. J. G. C. van den Borne. 2015. Effects of supplementation level and particle size of alfalfa hay on growth characteristics and rumen development in dairy calves. J. Anim. Physiol. Anim. Nutr. (Berl.) 99:553-564.

Mirzaei, M., M. Khorvash, G. R. Ghorbani, M. Kazemi-Bonchenari, A. Riasi, A. Soltani, B. Moshiri, and M. H. Ghaffari. 2016. Interactions between the physical form of starter (mashed versus textured) and corn silage provision on performance, rumen fermentation, and structural growth of Holstein calves. J. Anim. Sci. 94:678-686.

Montoro, C., E. K. Miller-Cushon, T. J. DeVries, and A. Bach. 2013. Effect of physical form of forage on performance, feeding behavior, and digestibility of Holstein calves. J. Dairy Sci. 96:1117-1124.
Nasrollahi, S. M., M. Imani, and Q. Zebel. 2015. A meta-analysis and meta-regression of the effect of forage particle size, level, source, and preservation method on feed intake, nutrient digestibility, and performance in dairy cows. J. Dairy Sci. 98:8926-8939.

Nemati, M., H. Amanlou, M. Khorvash, M. Mirzaei, B. Moshiri, and M. H. Ghaffari. 2016. Effect of different alfalfa hay levels on growth performance, rumen fermentation, and structural growth of Holstein dairy calves. J. Anim. Sci. 94:1141-1148.

Porter, J. C., R. G. Warner, and A. F. Kertz. 2007. Effect of fiber level and physical form of starter on growth and development of dairy calves fed no forage. Prof. Anim. Sci. 23:395-400.

Rosenthal, R. 1979. The "file drawer problem" and tolerance for null results. Psychol. Bull. 86:638-641.

Terré, M., L. Castells, M. A. Khan, and A. Bach. 2015. Interaction between the physical form of the starter feed and straw provision on growth performance of Holstein calves. J. Dairy Sci. 98:1101-1109.

Terré, M., E. Pedrals, A. Dalmau, and A. Bach. 2013. What do preweaned and weaned calves need in the diet: A high fiber content or a forage source? J. Dairy Sci. 96:5217-5225.

Viechtbauer, W. 2010. Conducting meta-analyses in R with the metafor package. J. Stat. Softw. 36:1-48.

Žitnan, R., J. Voigt, U. Schonhusen, J. Wegner, M. Kokardova, H. Hagemeister, M. Levkut, S. Kuhla, and A. Sommer. 1998. Influence of dietary concentrate to forage ratio on the development of rumen mucosa in calves. Arch. Tierernahr. 51:279-291. 